\title{
Research on Construction of Management and Control System of Electricity Bill Risks in Power Grid Enterprises under Energy Conservation and Emission Reduction Principle
}

\author{
Yimin Liu \\ Business and Management Department, North China Electric Power University, Beijing 102206, China \\ Haiyang Hou \& Kun Zhou \\ Business and Management Division, North China Electric Power University, Baoding 071003, China \\ Jinpeng Liu \\ Business and Management Department, North China Electric Power University, Beijing 102206, China \\ E-mail: hbdlljp@163.com
}

Received: May 13, 2011 Accepted: May 24, $2011 \quad$ doi:10.5539/ijbm.v6n8p287

\begin{abstract}
As the subject of long-term stable development of the electric power industry, the power grid enterprises are holding the important mission of power transmission. Their secure and stable operations play a very important role in the entire electricity production and consumption system. This paper analysed the enormous profit risks of electricity grid enterprises under the influence of implementing the current policy of energy saving and further studied significance of constructing management and control system of electricity bill risks from aspects of organization and institution construction, reporting system construction, information system construction, supervision and evaluation and continuous improvement mechanism construction, as well as risk cultural system construction. These careful studies will create favorable conditions for strengthening risk management in power grid enterprises.
\end{abstract}

Keywords: Energy conservation and emission reduction, Power grid companies, Electricity bill risk, Management and control system

\section{Introduction}

In recent years, energy conservation and emission reduction principle deepens in social production and life. In essence, it is to save material resources and energy resources, as well as to reduce waste and environmentally harmful emissions. Furthermore, it was presented in China that during the period of "Eleventh Five-Year" consumption per unit of GDP was to be reduced by about $20 \%$, and the total discharge of major pollutants by $10 \%$. For a long time, electricity bill between power grid companies and electricity tariff customers is settled by "first use, post-paid" model, which result in difficulties for power supply enterprises to recover bills. Moreover, with the continuous implementation of energy saving and emission reduction policy, the number of high energy consumption enterprises is reducing, and for a large number of small and medium enterprises, the living environment is deteriorating and they are even bankrupt, resulting in increasing cases of being in default of electricity bills. Affected by the national industrial policy adjustments and changes in international economic situation, some big electricity customers experience increasing difficulties, and it is difficult for them to make timely and actively payment of electricity bill. In the future, iron and steel, building materials, chemicals, automobiles, electrolytic aluminium, real estate, textile and other industries, subject to the continuing impact of energy conservation and emission reduction policies, their industrial production capacity will be attacked continuously and the laggards will be washed out, which leads to possible strand breaks between upstream and downstream industries and new edfault chains come into being. As a result, it is more complex and difficult to collect electricity bill, new risk of default is increasing, and it is more difficult to recover old default bills caused mainly by high energy consumption enterprises. The increasing difficulties to recover electricity bills will promote directly the expansion of corporate earnings risk, which will seriously affect the profits of electricity grid enterprises. Arrears takes a lot of cash flow, reduces the companies' solvency, increases the size of loans and financial costs, and greatly affects the capital operation space and efficiency. Therefore, it is significant to strengthen the construction of risk management and control system in electricity grid enterprise. 


\section{Necessity and significance of construction of electricity bill risk management and control system}

\subsection{It is operation basis for electricity grid enterprises}

At present, energy saving and emission reduction policies is implementing step by step. Many large enterprise customers to power grid enterprises is facing enormous production and management crisis. Economic reconstruction, further promotion of energy saving and emission reduction policies and drop of high-energy industries are all great challenges to profits of electricity grid enterprises. Due to the increasing risk of the new electricity bill arrear, the old electricity bill arrear is more and more difficult to recover. Power bill recovery system is the fundamental source of corporate income and is the base of protecting the normal operation of the business. Therefore, under the new situation, risk management is the best choice for electricity grid enterprises to bail out.

\subsection{It is a necessary requisition of risk management of State electricity grid}

State Grid Corporation launched the risk management strategy and risk management solution plans, and has implemented risk management research comprehensively. Electricity grid companies face the risk of electricity bill management, the study electricity risk management system is both the companies' important mission and fundamental responsibility and is good chance for companie to show themselves as an good example. With the volatility of economic growth and economic reconstruction, as well as the fact that electricity can not be stored, the low elasticity of demand and short-term changes in demand and other characteristics, power companies face increasing risk of power purchase and power supply. During this special period, the effective recovery of electricity bill is particularly important. Therefore, only good electricity risk management can ensure the stability of companies' performance and implement the mission of comprehensive risk management of the national electricity grid.

\subsection{It is the precondition of enhancing electricity grid enterprises' development}

Electricity bill is the only income for these kinds of enterprises and is the ultimate expression of business results. Electricity bill recovery activities are the most important aspects to maintain the simple reproduction of power and to achieve expansion of reproduction to ensure social stability and to obtain the basic guarantee for its effectiveness. At present, in various degrees at all levels of power enterprises, there is a"snowball-like" huge electricity bill arrears and many arrears have become "bad debt", "bad" or even "dead accounts." Huge arrears have become great burden to power companies and have a big affect on the sustainable development of enterprises. Furthermore, they have tied the healthy and orderly development of local economy. Therefore, it is necessary to implement electricity bill recovery risk management and to improve risk control ability for ensuring the coordinated, scientific and sustainable development of enterprises and for promoting enterprises' business development.

\section{Construction of electricity bill risk management and control system}

\subsection{Construction of electricity bill risk management and control organization}

Under the guidance of electricity grid enterprises' overall business objectives, at the business level, the fundamental sections and business departments should be responsible for identifying electricity bill risk factors that exist from the source in the process of business proceeds; at management level, the power costs risk management sections and risk management committees are the main organizers from the perspective of risk management, who should be liable for constructing the information management system in order to integrate risk management and information management; at the decision-making level, the internal audit departments and audit committees are the supervisors and assessors, they should support their overall process of strategy development from the perspective of enterprises' wide risk assessment and control. There is the formation of all aspects of enterprise systems and levels, including three kinds of protection to risk management of electricity bill, top-down risk control and risk prediction of electricity bill, the strategic bi-directional parallel electricity bill risk management objective system, all of which will maximize the overall management of electricity bill.

\subsection{Construction of reporting system of electricity bill risk management and control}

Electricity bill risk management reports is the carrier of information and communication of risk management. It is the collection of information and effectively internal and external communication by power enterprises in the whole process of electricity bill risk management. Information and communication is a dynamic process and it needs to set up a sustainable electricity bill risk reporting system.

Electricity bill risk reporting system includes following parts:

(1) Report of electricity risk management situation. The main contents includes construction of electricity risk management system for which the reporter is responsible, the occurrence of risk events, risk control effect and advice to improve the effectiveness of electricity bill management.

(2) Report of electricity risk monitoring. Electricity bill risk monitoring report is one that of a risk of supervision and inspection.

(3) Report of electricity risk auditing. Electricity bill risk audit report is one that of a risk of audit. 
(4) Report of electricity risk early warning. Early Warning Report is a tool of comprehensive risk management which will measure degrees of deviation from warning line and giving warning signals.

(5) Report of electricity bill risk event. An analysis of the emergency will provide the basis for the electricity bill risk warning information, and is an important component of dynamic monitoring of electricity bill risks.

\subsection{Management and control system construction of electricity bill system}

According to the basic needs of electricity bill risk management, electricity bill risk management system can be divided into five parts as follows: information collection, risk assessment, data dictionary, risk and decision-making and system management information.

\section{(1) Information collection}

According to the power supply contracts, the customer's business registration data, industry classification, business nature and amount of payment methods and payment quota will be entered into the system; and customers' prepayment of electricity bill will be supervised automatically and be underlined if they pay later or are possible to pay later by any information in accordance with national industry policy, the enterprise market information and the meter reading feedback. Power supply enterprises can get feedback of evaluation according to scores calculated by the assessment model.

\section{(2) Risk Assessment}

The graphs indicates the credit risk, credit risk charts and warning list of clients who make arrears will be drawn through the calculation of a risks by assessment model according to data collected by the information acquisition module. All risk assessment will be done automatically by the system. Operators only need to adjust the evaluation model by using the data dictionary, and entering the customers' information collected dynamically by the module.

\section{(3) Data dictionary}

Comprehensive evaluation will be made based on various information of enterprises by percentage according to the system. It includes three main aspects of the evaluation contents: basic information, dynamic situation and payment information. System administrators can adjust the weight of each content in the assessment model. Basic information includes corporate information, industry classification, sub-scores set up by system administrators, scores of any of the categories adjusted by system administrators; dynamic information can always increase the assessment rules, set its weight in the sub-categories, put in formula based on evaluation requirements and provide information that involves the project name, unit and other information used in editing.

(4) Risk and decision-making information database

Risk and decision-making information database contains the historical occurrence of the electricity power enterprise risk, as well as management and decision-making information. The information is a significance reference to decision-making, especially electricity bill policy-making of these enterprises in the future.

\section{(5) System management}

System management module application is the basic one for system operation and usage. Right management system provides system right permissions, maintenance department staff, distribution of group and personnel to ensure the legitimacy of the system users, security and database security. System operators or authorized customers have rights to modify the coefficient of risk assessment model. System administrators adjust the grouping of operators at any time, edit grouped information according to practical tasks. This system uses the full dynamic menu technology, only system administrators can set up personnel, departments and distribution of tasks. Staff who use the system login name and initial password and give the permissions to a user who will perform the function menu.

\subsection{Construction of supervision and evaluation and continuous improvement mechanism of electricity bill risk}

The object of supervision and evaluation mechanism of electricity bill risk management is to construct machinism of electricity bill risk management, to run internal audit and external audit on operating effects, to put forward the direction of continuous improvement and measures to protect the electricity risk management system when combined with benchmarking experience, all of which will play a strategic role in promoting the achievement of objectives.

Construction of supervision and evaluation mechanism focuses on operation and maintenance of electricity bill risk management, updating of risk database, the effectiveness of risk response plans, the overall risk strategy and so on. Enterprises should focus on significant risks, major events and important decisions, important management and business processes, make supervision on the initial information on risk management, risk assessment, risk management strategy, the key control activities and risk management solutions, test the effectiveness of risk management by using pressure Testing, return to the test, walk through risk control, self-assessment test and other methods, and improve the defects in a timely manner based on changing circumstances. 


\subsection{Culture construction of electricity bill risk management and control system}

Electricity bill risk management activities and results are presented by way of the spirit, system, behavior, physical dimensions, all of which work together to build risk management activities into a complete electricity bill cultural system.

\section{(1) Spirit level}

Electricity bill risk management culture in the spirit of the layer is known as the spiritual culture of electricity bill risk management. Compared with material culture, behavior culture and system culture of electricity bill risk management, spiritual culture is at deepest level and becomes the core of electricity bill risk management culture. From the content perspective, the spiritual culture of electricity bill risk management is formed in the process of understanding of and prevention to risks in the long term. It is the spirit, perceptions and theoretical results of the risks. From the extension of terms, the spiritual culture of electricity risk management includes spirit of electricity bill risks, values and concept of bill risks, control perception of electricity bills, and theoretical and systematical science of electricity bill risk management.

(2) System level

The most basic and stable part of electricity bill risk management is system management. Here the system includes the external and social constrained alegal system and the internal constrained rules and regulations. However, the this kind of basic and stable electricity risk management is based on the system itself and behavior cost. The trend of abiding laws and disciplines is the basis of risk management practices. Internal consistency of abiding laws and disciplines and being trustworthy and professional is the fundamental requirement of behavior culture of electricity bill risk management. For enterprise risk management culture, its organizational structure and the construction of the system is the fundamental part to build a platform of spiritual culture, behavioral culture and material culture.

(3) Behavior level

Behavior culture is ultimately manifested by individual behavior and of its mutual influence. Formation of behavior of electricity risk management culture must seize the man - the role of example and the effects of group interaction. First of all, we should pay attention to electricity bill risk management behavior of super and medium level leadership, in particular, No.1 person of the board members to set an example; secondly, we should pay attention to behavior of excellent risk manager; finally, enterprises should pay attention to the interactive sessions of group behavior, through a variety of mass propaganda, training, competition, testing and other activities, and group interaction in shape the staff quality, behavior and fashion of risk management.

(4) Physical layer

The ultimate goal is of electricity bill risk management is to minimize the risk of electricity bill recovery in order to ensure power enterprises to achieve maximum revenue results. Therefore, it is necessary to recall the concept of electricity bill recovery and deep it into heart of each power company employee. Of course, when the electricity bills are recovered well, the enterprises should reward the employees who are good at recovering electricity bill and at managing electricity bill recovery risks, and furthermore offer them some appropriate material support. In addition, for the electricity consumers who can make early or prompt payment of electricity bills, the power enterprises should offer them some material support in order to encourage them to pay electricity bills on time or ahead of schedule later on.

\section{Conclusion}

The paper made a rational analysis of the great challenges caused by the implementation of energy conservation and emission reduction polices to power grid enterprises from the prospective of electricity bill recovery, as well as of significance of electricity bill recovery to electricity grid enterprises in China. It focused on some importance issues related to construction of electricity bill risk management and control system, which will set up foundation to improve the awareness of risk prevention and strengthen risk management skills.

\section{References}

Ai, Jing. (2006). Brief Analysis on Reasons and Solutions of Issues on Electricity Bill Recovery. Report on Scientific Innovation, (07).

Cai, Guanzhong. (2005). Credit Classification of Electrical Power Customers. Management of Rural Electricity, 12 .

Fan, Zhaolin. (2009). Risk Control of Electricity Bill Recovery. Rural Electrical Engineering, (04).

Sun, Yang. (2007). Brief Analysis on Electricity Bill Recovery for Power Supply Enterprises. Electrical Power of Hei Longjiang Province, (06). 